Running head: MENTAL HEALTH LIVED EXPERIENCE IN SOCIAL WORK EDUCATION

A Journey of Embedding Mental Health Lived Experience in Social Work Education Kate Dorozenko, Sophie Ridley, Robyn Martin and Lyn Mahboub School of Occupational Therapy and Social Work, Curtin University, Perth, Australia.

\begin{abstract}
Author Note
Correspondence concerning this article should be addressed to Kate Dorozenko, School of Occupational Therapy and Social Work, Curtin University, Perth, WA 6102, AUSTRALIA. Email: kate.dorozenko@curtin.edu.au

We would like to thank the Lived Experience Consultants involved in the Valuing Lived Experience Project for their time and expertise. We also acknowledge Richmond Wellbeing, the School of Occupational Therapy and Social Work and Curtin University's Teaching and Learning for their ongoing support.
\end{abstract}




\section{A Journey of Embedding Mental Health Lived Experience in Social Work Education}

The value of learning from mental health lived experience is widely acknowledged, however, the nature of lived experience involvement in Australian social work education seldom extends beyond guest lecturing. Further, few opportunities exist that build the capacity of people with lived experience to become educators within tertiary settings. In this paper we present the Valuing Lived Experience Project (VLEP), an initiative led by a Lived Experience Academic that seeks to systematically and meaningfully embed lived experience into the social work curriculum at a Western Australian university by providing significant opportunities for the capacity building of both individuals with mental health lived experience and academics. Given the relative infancy of service user involvement in Australian social work education, the VLEP offers a number of opportunities for reflection and consideration. A longstanding partnership between a Lived Experience Academic and Social Work Academic is described, the activities and key learnings of the VLEP to date are outlined, and we offer our reflections on challenges encountered throughout the journey. We hope that our experiences and learnings can be drawn upon to progress lived experience participation in tertiary settings and further legitimise lived experience involvement in the education of social workers.

\section{Keywords}

Lived experience education, capacity building, family, service user, personal recovery.

\section{Introduction}

There is widespread consensus that the involvement of people with lived experience (PLE) in the education of social workers and other mental health professionals represents good practice (Bell, Whitehead, Aslani, Sacker, \& Chen, 2006; Duffy, Das, \& Davidson, 2013; Happell et al., 2015). Learning from lived experience provides students and practitioners with unique insights that facilitate professional compassion, expand understanding, challenge negative and stigmatising 
attitudes, and facilitate skill development (Bell et al., 2006; Beresford \& Boxall, 2012; Happell \& Roper, 2003; Irvine, Molyneux, \& Gillman, 2015).

Research exploring the views of university academics, reports that the form of expertise that is brought by Lived Experience Educators can challenge some academics (Basset, Campbell, \& Anderson, 2006; Felton \& Stickley, 2004). As a consequence of this, it has been argued that academic staff may 'gate keep' lived experience involvement in education (Happell et al., 2015). These points draw attention to the role of power relations within academia and the potential for Lived Experience Educators to unsettle these structures and dynamics (Beresford \& Boxall, 2012; Felton \& Stickley, 2004). Knowledge derived from medicalised epistemology (and the associated notions of pathology and reduced competency) pervades mental health education, reinforcing beliefs that PLE of mental distress are unreliable, dangerous and lack the capacity to occupy esteemed roles such as educator (Basset et al., 2006; Felton \& Stickley, 2004). Finally, some academics have argued that formal processes and clear guidelines which preserve service user autonomy and avoid tokenistic involvement are needed to progress lived experience education (Happell et al., 2015).

In considering the views of PLE, a lack of training has been identified as a significant issue, resulting in PLE feeling unsupported and unprepared for their role (Basset et al., 2006). Historically and typically, Australian service users and family members provide guest lectures sharing their experiences of 'mental illness' and the mental health system, with little attention paid to building capacity prior to educational involvement (Happell et al., 2014; Happell \& Roper, 2009). This ad hoc approach often leaves individuals needing to 'learn on the job' (Basset et al., 2006). This suggests that a change in culture within universities and academia is needed (Felton \& Stickley, 2004; Happell et al., 2015).

Where PLE are involved in tertiary education, several limitations have been noted in the literature. First, studies from the discipline of nursing tend to dominate; $73 \%$ of studies compared to 7\% in social work (Happell et al., 2014), which raises questions about the transferability of these findings to social work. Second, student and academic perspectives pervade, while the voices of PLE 
are comparatively muted (Happell et al., 2014; Meehan \& Glover, 2007). Third, within the literature, the empowerment of PLE is often emphasised as a reason for lived experience inclusion in social work education, yet their involvement is considered an 'added extra'; rather than essential, if funding permits (Felton \& Stickley, 2004; Robinson \& Webber, 2013). This can lead to tokenistic involvement, whereas the primary objective should be to harness the expertise of lived experience to progress social work education (Robinson \& Webber, 2013). Fourth, there is a dearth of studies which deeply explore the underlying assumptions, values and attitudes that drive resistance and receptiveness to mental health service user involvement (Felton \& Stickley, 2004; Happell, 2014; Happell et al., 2014). Finally, studies which document the process of how lived experience can be systematically embedded within the curricula and offer reflections on successes, tensions and challenges are not readily available to guide practice (Felton \& Stickley, 2004).

The act of meaningfully involving PLE in social work education directly mirrors the professions' values of respect, partnership and self-determination (Scheyett \& Diehl, 2004). A study conducted by Duffy and Hayes (2012) reported that first year social work students' interactions with service users and family members representing a variety of fields were the most significant influential factor in the students' knowledge and values development. More locally, a small scale Western Australian study found that learning from lived experience is essential to the development of critically informed understandings of mental distress (Author, Author, \& Author, under review). It has been argued that dominant views of mental distress and associated practices that are informed by biomedical understandings need to be problematised within social work education in order to avoid obscuring alternative frameworks of understanding (Beresford \& Boxall, 2012). Furthermore, it is essential that students see and hear from people who can share their stories of recovery from mental ill health and come to understand first hand that people can and do recover.

The inclusion of PLE in social work education also reflects national and international policy directives which tout personal recovery approaches. It is, however, important to note that despite gaining prominence in political rhetoric, 'personal recovery' as a concept has been problematised by 
some as being ambiguous, value-laden, and dependent on notions of deficit (Beresford, 2015; Harper \& Speed, 2012). It has also been argued that the emphasis on the individual in personal recovery marginalises those collective, structural experiences of inequity and injustice that contribute to mental distress (Beresford, 2015; Harper \& Speed, 2012). We agree that the co-option of personal recovery to serve neo-liberal aims, and the subsequent invisibility of structural factors that underlie many experiences of mental distress, must be continually interrogated within social work curriculum, learning and teaching.

In Australia, social work education is based on a four year Bachelor of Social Work or a two year qualifying Master of Social Work university based degree. While social work is not a registered profession, the Australian Association of Social Workers' accredits the course work and 1150 hours of supervised fieldwork placement within educational programs. Mental health service user involvement in the planning and delivery of social work education is recommended, but not mandated, by the Australian Association of Social Workers (Australian Association of Social Workers, 2008). While the value of learning from lived experience has been widely acknowledged, the nature of service user and family involvement in Australian health sciences education seldom extends beyond guest lecturing (Happell et al., 2015; Moxham, McCann, Usher, Farrell, \& Crookes, 2011). In contrast to the Australian context, service user and family involvement in social work education in the United Kingdom is said to be an "established feature" (Duffy \& Hayes, 2012, p. 368) and includes active involvement in design, management, delivery, monitoring and evaluation of social work programs (Duffy \& Hayes, 2012). However, it is important to note that there is debate and contestation about what constitutes meaningful involvement of PLE in social work education (Robinson \& Webber, 2013).

The relative infancy of service user involvement in Australian social work education offers a number of opportunities for reflection and consideration. A key point is the importance of lived experience involvement being deeply valued and avoiding tokenistic attitudes and approaches (Beresford \& Boxall, 2012; Scheyett \& Diehl, 2004). The meaningful involvement of PLE in tertiary 
education settings requires a reconsideration of the relationships between service users and academics, and the unsettling of existing power structures within academia (Felton \& Stickley, 2004; Happell \& Roper, 2009). Involvement as a Lived Experience Educator can provide significant opportunities for capacity building and development of both service users and academics, and holds promise for service system improvements (Meehan \& Glover, 2007).

This paper describes an ongoing project which is attempting to embed lived experience into social work curriculum in XXXX, Western Australia. We begin by reflecting on the partnerships underpinning the initiative, called the Valuing Lived Experience Project (VLEP), which aims to systematically and meaningfully embed lived experience education into social work and occupational therapy curriculum in the first instance. While detailing the activities of the project, we offer our reflections on the challenges and achievements. Finally, we share our key learnings, goals and plans for the VLEP.

\section{The Foundations}

The VLEP emerged from the long-standing partnership between two academics; one employed as a Lived Experience Academic (LEA) and one as a Social Work Academic (SWA) in the School of Occupational Therapy and Social Work (the School) at XXXX University. The LEA and SWA first met in 2007 when they attended a five day, live in, recovery training program. From this meeting, their work together grew, starting with the LEA being invited by the SWA to engage in paid employment as a guest lecturer and share her lived experience, critical understandings of 'madness', and the hearing voices approach with final year social work students in a mental health and recovery unit. The two academics then worked with other academics from occupational therapy, nursing and psychology, to develop a Masters of Mental Health. While different standpoints were adopted in relation to 'mental illness' and mental distress within this group, the value of lived experience was held as central by the LEA and SWA. The post-graduate program was taken up by students with both lived and professional experience from a variety of disciplines. Due to staff changes, the LEA and 
SWA developed and delivered the majority of teaching in the course. Consequently, privileging lived experience came to be central in the teaching.

During this time, the LEA's position was cemented and extended beyond the Masters program. Within both the Masters and undergraduate social work teaching, this involved; coordinating units, creating unit outlines, developing and delivering lectures and workshops (including simulated learning on topics such as hearing voices), developing student assessments, marking student assessments and negotiating with industry partners to coproduce student learning and assessments. From the LEA's perspective, the journey from invited guest lecturer to equal partner has been an enriching and inclusive adventure, largely due to the partnership she had with the SWA. In this partnership, the LEA and SWA were able to share power, embrace each other's assets and blur the boundaries between the diverse knowledge that they each brought to the table.

While the LEA had a history in tertiary education (as both student and tutor), she had limited exposure to the full range of teaching and learning activities involved in a unit or course. At the request of the LEA, the SWA provided mentoring and support to the LEA in these areas. As a result, the partnership between the LEA and SWA grew and in turn, provided professional and personal development opportunities for the SWA. Particularly, it provided the SWA with a deep, rich and contextual understanding of the opportunities and challenges associated with embedding lived experience into social work curriculum. As a consequence of the work undertaken together and a deep respect for each other's world view, values and philosophy, the LEA and SWA frame their working partnership as a peer relationship.

Another activity the LEA and SWA coproduce is the supervision of research students, extending activities beyond the classroom into the research space. One successful research project examined the impact of learning from lived experience on social work students' practice during their first fieldwork placement (Author et al., under review). Findings suggested that learning from lived experience promotes social work practice which honours lived experience expertise and privileges 
personal recovery approaches. Students also identified ways in which lived experience learning influenced their ability to resist dominant biomedical cultures and disempowering practices. This project extended and broadened the LEA and SWA's understanding of the place of lived experience in the social work curriculum.

Despite the cessation of the Masters program, the School committed to the LEA role which led to the development of the VLEP. Underpinning the VLEP is the desire to create opportunities for other PLE to be involved in education within the School. Led by the LEA, the VLEP is founded on, and guided by, principles of coproduction (Slay \& Stephens, 2013). The VLEP aims to carry out an array of activities and events which build capacity of PLE (both individuals and family members) and academics within the School and broader university. This capacity building involves creating the conditions for PLE to become educators within tertiary settings, and creating the conditions under which academics can privilege and center lived experience in their teaching, learning and research activities.

In addition to the LEA, a project officer, the SWA and a mental health recovery researcher provide the backbone to the VLEP. Financial support has been garnered from the School, XXXX (a non-government mental health recovery service provider), and a university teaching and learning grant. The support by leaders and staff from within the School has been invaluable, providing encouragement and communicating their belief in the significance of the project and most importantly, in the value of lived experience. The LEA and SWA have sound networks and connections with service users and service providers, and the project is well regarded within the Western Australian mental health sector.

\section{Activities of the VLEP}

The following section describes the activities of the VLEP to date (see Figure 1) and the challenges encountered by the team on the journey to embedding lived experience in the School. The principles and values of participatory action research and coproduction have guided this project, facilitating the empowerment of those involved and enabling change and improvements to be made to the 
project. This also enabled a reflective approach which contained feelings of uncertainty and anxiety in what is new and unchartered territory for the VLEP team. Without guidelines to follow, much of our learning has been through trial and error. It is expected that planned activities will change as the project progresses and evolves, and that this reflects the dynamic approach which is central to the project.

\section{Discussion forum on lived experience involvement in education}

In July 2015, PLE were invited to attend a discussion forum hosted by the School. The forum sought to gauge community interest in lived experience involvement in tertiary education, create a space for dialogue and networking, and showcase the work of PLE already involved in the education of professionals. Thirty eight people attended the event, and PLE were invited to be involved in the VLEP, future events and educational opportunities. The atmosphere of the forum was one of excitement, enthusiasm, and robust discussion. Importantly, the forum offered an encouraging environment where lived experience was legitimated and categorised as expertise. Further, all who attended the forum were convinced of the value of lived experience involvement in education and shared a passion and commitment to enact change in the university and mental health contexts. Following this event, more than 65 PLE, service providers, academics and researchers expressed interest in the project and receive newsletters providing updates on VLEP activities, achievements and opportunities to be involved in the project.

\section{Pilot tutorial series}

Following on from the discussion forum, a two-part pilot tutorial series was designed and delivered by the LEA to 12 individuals who expressed an interest. The aim of this tutorial series was to capitalise on the interest generated from the discussion forum and provide an introduction to those wanting to pursue a future in lived experience education. It was also anticipated that the feedback provided from the participants would inform the development of a larger capacity-building unit to upskill future Lived Experience Educators. The tutorials were facilitated by the LEA and topics presented and discussed within the group included the history of the service user movement in 
mental health, different frameworks of understanding 'madness', and personal recovery. One of the tutorials elicited critique of the term 'madness', which then produced a rich discussion of the Mad Pride Movement, of which some participants were unaware. This example highlighted the importance of understanding history from a critically informed stance as it underpins and legitimates a Lived Experience Educator role. Tutorial participants reported that the content was useful and particularly valued the critical thinking elements, provision of resources and the knowledge and skills of the LEA who delivered the tutorial series.

\section{The formation of an advisory group}

Following the forum and pilot tutorial series an advisory group was formed in October 2015 to guide the design and development of a unit of study on becoming a Lived Experience Educator. On completion of the unit participants will be able to offer strategic input into curriculum development; plan and deliver lectures, tutorials, workshops and laboratories; develop and mark student assessments; and work in partnership with university academics to create opportunities for lived experience teaching and learning. While the initial focus of the VLEP is lived experience in mental health, it is anticipated that this will be broadened across a range of sites of social work practice such as domestic and family violence, older people, children and young people, disability, culturally specific practices and families.

Recruitment to the advisory group was by expression of interest, and individuals were required to outline; their consultancy experience and educational experience, knowledge of the service user and family movement, understanding of personal recovery (as differentiated from clinical and social recovery), and to demonstrate a critically informed view of 'mental illness'. Shortlisted applicants attended a brief interview with the LEA and were required to demonstrate that they could attend all five meetings. The advisory group comprised the LEA as project lead, seven Lived Experience Consultants, four social work academic staff and one occupational therapy student. The Lived Experience Consultants who sat on the advisory group had a wealth of knowledge and experience in the areas of mental distress, service delivery, training, and personal recovery. Many of 
the Consultants also had qualifications in teaching and education, training, and social work.

Consultants were paid an industry standard rate for their involvement.

In order to coproduce a safe and trusting environment in the advisory group, a number of strategies were employed. In addition to the collaborative development of a group safety agreement, a co-chair was appointed to ensure sharing of power and promote openness in meeting facilitation, and multiple opportunities for feedback were created. Lived Experience Consultants were invited to remain for a debriefing session after the meeting. At the last meeting, a brief survey was given to advisory group members inviting feedback on the process. This data was collated by the project officer and analysed. Overall, members reported that they experienced the advisory group process as safe, respectful and as validating of their experiences and knowledge. Members credited this largely to the strong leadership and skilled facilitation of the LEA and the shared vision of the group.

On completion, the advisory group had established four learning outcomes (or education priorities) for the Lived Experience Educator unit (Table 1). The focus or themes of the six learning modules that comprise the unit were also developed (Table 2). In their feedback, advisory group members commented that they were impressed by what was achieved in just five meetings and attributed this productivity to the clear assignment of tasks and strong sense of accountability within the group.

The issue of eligibility for the unit was raised by a number of advisory group members and stimulated robust discussion. Some argued that only individuals with prior teaching experience, pedagogical knowledge and skills, and confidence using technology should participate in the unit. Others contended that eligibility for the unit should be broadened to be inclusive of all with an interest in the education of future mental health professions. While consensus on the issue was not reached, the discussion demonstrated that individuals may have different motivations for undertaking training to become a Lived Experience Educator. The advisory group agreed that given 
the nature and trajectory of individual recovery journeys, some people undertaking the unit may require scaffolding to support 'unit readiness'.

\section{The lived experience simulation project}

Running parallel to the advisory group was the lived experience simulation project. While competitive funding was initially obtained for the project, contract and ownership requirements imposed by the national funding body led the VLEP team to decline this grant funding (discussed later). Fortunately, the School funded the simulation project. Simulation is an educational tool that enables students to learn and develop skills in a safe and controlled environment (Alinier, Hunt, Gordon, \& Harwood, 2006). Simulation resources are often video-recorded clips which feature people who act or simulate different situations that the students can then learn from.

Modelled on the work of Orr, Gallagher, Stein-Parbury, Gill and Heffernan (2015), the lived experience simulation project produced four video-recorded vignettes featuring people with mental health lived experience. The LEA participated in one of the simulations and the SWA interviewed people on their lived experience. Topics discussed by the PLE in the simulations included lived experience of 'mental illness', service delivery experiences, recovery journeys and best practice approaches. This simulated learning tool will provide a powerful experiential learning opportunity and a useful introduction to mental health lived experience, particularly in disciplines where fieldwork placements occur much later in the course. These vignettes will be trialled and evaluated in the School initially, and then made available to all other health science disciplines. Learning activities to accompany the simulations are currently being developed.

Unlike the majority of simulation tools, the people featured in the vignettes were not paid actors, but people with lived experience of mental distress. By way of initialising support, significant attention was paid to discussing, exploring and unpacking what would happen before, during and after filming. As a result of these conversations, one person elected to not continue prior to filming. While this created some disruption in project plans, it was viewed by the VLEP team as a sign of informed choice by the individual. Academic and lived experience colleagues from another 
Australian university who had previously produced lived experience simulations provided input and support prior to commencing filming. Particular issues raised in this consultation by the Lived Experience Educator included having conversations about a person's right to self-censor and share what they were comfortable with; confidentiality; role and identities in different contexts (such as being a service user in one context and a student supervisor in another); creating a safe environment; and the importance of debriefing following the live simulation.

With this feedback in mind, the issues of confidentiality and anonymity were explored with simulation participants at length and formed the employment contract. Participants had the option of having their face shown or pixilated, and of using a pseudonym. The prompt questions were provided in advance, and it was emphasised that they were not obliged to answer questions that were uncomfortable or revealing. Participants were advised that they would receive a copy of the final product; and while the University retained ownership of the resource, the participant could use it for non-commercial purposes.

\section{Tensions and Key Learnings}

In this section, we present some issues encountered during the VLEP activities and subsequent key learnings.

During the pilot tutorial series, notions of potential co-option into academia were explored when the feeling of not wanting to be "turned into an academic" was expressed. Underpinning this was the potential discomfort with the perceived elitism and prestige associated with the role and how this can collide with one's identities or positioning as a non-academic. It was also argued that as a Lived Experience Educator one should not be required to pay lip service to the mental health system or self-censor one's lived experience to make it more palatable to an audience of university students and academics. This sentiment is underscored by Felton and Stickley (2004) who reported that lecturers did not want service users to become too 'professionalised' and expressed aversion to service users being trained as educators. These lecturers argued that 'career service users' were too distanced from their experiences and did not represent individuals with 'mental illness', and as such 
would be of little value to students. Paradoxically, service users who were still actively engaged in services or receiving treatment were also considered problematic by lecturers who suggested they may be too vulnerable or too unpredictable to participate in teaching (Felton \& Stickley, 2004). We agree with Happell and Roper (2009) that it is essential for service users' involved in tertiary education to be afforded genuine autonomy and the safety to share the 'service user perspective'. We feel (and this is also echoed by many PLE involved in education) that adequate preparation for all is crucial to ensuring that lived experience is valued and respected in this space.

Another issue encountered related to the payment of PLE who were employed as Consultants in the advisory group. Concerns surfaced within the advisory group that the payment of sitting fees had the potential to interfere with welfare and income support payments (also found by Basset et al., 2006). Duffy and Hayes (2012) drew attention to the irony of this situation, stating that service user remuneration is "... not helped by a benefits system which mitigates against their working as social work educators despite government rhetoric about personalization and coproduction" (p. 371). To circumvent this issue, some PLE involved in the VLEP opted to be paid with vouchers for major retailers. Tew, Gell, and Foster (2004) offer other practical strategies to ensure that service users are renumerated for their contribution, such as spreading payments over a longer time period so that the earnings threshold is not exceeded.

Finally, issues arose when creating an employment contract for the PLE involved in the simulation project that met the requirements of the research grant (particularly around intellectual property), while being accessible for service users. The VLEP team developed a contract that clearly described reciprocal responsibilities that was concise and utilised accessible language. This contract was then sent to the University legal section for approval. Following conversations between the legal team and the simulation grant funding body, the contract developed by the VLEP was rejected. To meet the grant requirements, a new contract was produced that was full of jargon, complicated, lengthy and required professional indemnity and public liability insurance, which made the Lived Experience Consultants ineligible. To the disappointment of the team, the simulation grant funding 
body adopted a risk averse stance and was unwilling to modify this contract. The team felt strongly about maintaining the integrity of the project and honouring lived experience, so rather than adopting this contract, the decision was made to forgo the grant funding and seek funding elsewhere. This issue highlighted to the VLEP team how bureaucracy and complex and inflexible systems can be not only be distancing for service users, but also discriminatory. This exemplified the need to affect change at a systemic level.

\section{Next Steps and Anticipated Challenges}

The VLEP team were successful in securing a grant to work with Lived Experience Consultants in developing specific content, learning approaches and activities for the Lived Experience Educator unit. This unit will commence in July 2016. The team feel that it is important that those individuals who participate in the Lived Experience Educator unit are formally recognised for this learning. The unit will require a significant time and emotional investment from participants. Participants may also wish to use the skills and knowledge developed in this unit within the broader mental health community as Consultants and Trainers. Achieving accreditation for this unit would allow participants to seek recognition of prior learning enabling pathways to higher education, whilst further legitimising the expertise of service users and family members. Finding pathways to accreditation for the unit is something the VLEP team will pursue.

The team will also develop 'Valuing Lived Experience Guidelines' to support academic staff who wish to embed lived experience education into existing curricula. Central to these guidelines will be a focus on preparing students to learn from lived experience and debriefing for the Lived Experience Educators. To accompany these guidelines, a conversation hub will be established within the School to provide the opportunity for academics, researchers and other staff members to discuss the place, purpose and impact of lived experience learning across all units. Although most university academics broadly agree that service user and family involvement in education is valuable (Happell et al., 2015), a range of reasons for not advancing service user and family involvement in tertiary education are put forward. Some of the cited barriers include the so-called 'attributes' of people 
with mental health issues and the degree of 'representativeness' of views expressed by PLE (Felton \& Stickley, 2004). We believe that many of these perceived barriers can be overcome through the education and capacity building of academics, and supporting them through the provision of resources and tools. For academics to fully engage in this initiative, more than a superficial or fleeting interest in lived experience education is needed. A transformation of thinking and a change in culture is required (Felton \& Stickley, 2004; Happell, 2014).

In 2016, the simulations featuring service users and family members will be rolled out within the School, which also includes the discipline of occupational therapy. The team have already received request from another School to use these simulations, and while we are appreciative of this interest and enthusiasm, we are committed to ensuring the integrity of the learning tool when it is used across disciplines. To address this concern, briefing, monitoring and mentoring will be provided by the LEA and SWA to other disciplines who choose to share the simulations with students. In addition, coproduced learning materials and activities will be developed to accompany the simulated learning tool.

Research and evaluation of the VLEP will be ongoing. In 2016, the team will conduct research exploring the experiences of participants who undertake the Lived Experience Educator unit. We also plan to further explore the experiences of Lived Experience Consultants involved in the advisory group for quality improvement. Future research will evaluate the impact of the lived experience simulations on student learning as well as the experience of the academics who implement the teaching tool. The VLEP journey will continue to be documented and disseminated. It is our hope that providing honest accounts of the tensions and challenges faced and the achievements and outcomes realised will assist others to meaningfully include lived experience in the curriculum.

Perhaps the greatest challenge faced by the team is ensuring the longevity and sustainability of the VLEP into the future. For the momentum of the lived experience education movement to continue it must be truly embedded in the curriculum and School and university processes. To do 
this, securing funding through nationally competitive grants and forming strategic partnerships with other universities and organisations is key. Communication with two other universities has commenced in regards to potential partnerships, along with organisations which champion mental health recovery, leading policy makers, and governing mental health bodies. Ultimately, we would like to extend lived experience education beyond the area of mental health to include service users and family members with lived experience of child protection services, homelessness, substance misuse, disability and the criminal justice system as others (e.g. Duffy \& Hayes, 2012) have done. Further, we would like to expand lived experience education beyond the discipline of social work to include other health science disciplines such as psychology, occupational therapy and nursing.

\section{Conclusion}

We argue that the idea of supporting people to become Lived Experience Educators' legitimises the role and highlights their expertise by experience, while simultaneously arming them with information about academic processes and protocols to enable deeper involvement. It is true to say that in Australia, PLE are involved in education and training in an array of ways across the mental health sector, however, we believe that providing resources and materials to build capacity of individuals seeking to be involved at an academic level can only enhance other areas of involvement that individuals are engaged in. We propose that part of this capacity building is also to challenge existing structures within universities, and strengthen the ability of academics to work with lived experience in broad and value based ways. 


\section{References}

Alinier, G., Hunt, B., Gordon, R., \& Harwood, C. (2006). Effectiveness of intermediate-fidelity simulation training technology in undergraduate nursing education. Journal of Advanced Nursing, 54(3), 359-369. doi:10.1111/j.1365-2648.2006.03810.x

Australian Association of Social Workers. (2008). Practice Standards for Mental Heath Social Workers.

Basset, T., Campbell, P., \& Anderson, J. (2006). Service user/survivor involvement in mental health training and education: Overcoming the barriers. Social Work Education, 25(4), 393-402. doi:10.1080/02615470600593675

Bell, J. S., Whitehead, P., Aslani, P., Sacker, S., \& Chen, T. F. (2006). Design and implementation of an educational partnership between community pharmacists and consumer educators in mental health care. American Journal of Pharmaceutical Education, 70(2).

Beresford, P. (2015). From 'recovery' to reclaiming madness. Clinical Psychology Forum, 268, 16-20.

Beresford, P., \& Boxall, K. (2012). Service users, social work education and knowledge for social work practice. Social Work Education, 31(2), 155-167. doi:10.1080/02615479.2012.644944

Duffy, J., Das, C., \& Davidson, G. (2013). Service user and carer involvement in role-plays to assess readiness for practice. Social Work Education, 32(1), 39-54.

doi:10.1080/02615479.2011.639066

Duffy, J., \& Hayes, D. (2012). Social work students learn about social work values from service users and carers. Ethics and Social Welfare, 6(4), 368-385. doi:10.1080/17496535.2012.654497

Felton, A., \& Stickley, T. (2004). Pedagogy, power and service user involvement. Journal of Psychiatric and Mental Health Nursing, 11(1), 89-98. doi:10.1111/j.1365-2850.2004.00693.x

Happell, B. (2014). Consumer participation in the education and training of mental health nurses. Queensland Mental Health Commission, November. http://www.qmhc.qld.gov.au/wpcontent/uploads/2015/05/Consumers-and-Mental-Health-Nurse-Education-Issues-Paper.pdf 
Happell, B., Byrne, L., McAllister, M., Lampshire, D., Roper, C., Gaskin, C. J., . . Lakeman, R. (2014). Consumer involvement in the tertiary-level education of mental health professionals: A systematic review. International Journal of Mental Health Nursing, 23(1), 3-16. doi:10.1111/inm.12021

Happell, B., \& Roper, C. (2003). The role of a mental health consumer in the education of postgraduate psychiatric nursing students: The students' evaluation. Journal of Psychiatric and Mental Health Nursing, 10(3), 343-350. doi:10.1046/j.1365-2850.2003.00599.x

Happell, B., \& Roper, C. (2009). Promoting genuine consumer participation in mental health education: A consumer academic role. Nurse Education Today, 29(6), 575-579. doi:http://dx.doi.org/10.1016/j.nedt.2008.01.004

Happell, B., Wynaden, D., Tohotoa, J., Platania-Phung, C., Byrne, L., Martin, G., \& Harris, S. (2015). Mental health lived experience academics in tertiary education: The views of nurse academics. Nurse Education Today, 35(1), 113-117. doi:10.1016/j.nedt.2014.07.006

Harper, D., \& Speed, E. (2012). Uncovering recovery: The resistable rise of recovery and resilience. Studies in Social Justice, 6(1), 9-25.

Irvine, J., Molyneux, J., \& Gillman, M. (2015). 'Providing a link with the real world': Learning from the student experience of service user and carer involvement in social work education. Social Work Education, 34(2), 138-150. doi:10.1080/02615479.2014.957178

Meehan, T., \& Glover, H. (2007). Telling our story: Consumer perception of their role in mental health education Psychiatric Rehabilitation Journal, 31(2), 152-154. doi:10.2975/31.2.2007.152.154

Moxham, L., McCann, T., Usher, K., Farrell, G., \& Crookes, P. (2011). Mental health nursing education in preregistration nursing curricula: A national report. International Journal of Mental Health Nursing, 20, 232-236. doi:10.1111/j.1447-0349.2010.00735.x

Orr, F., Gallagher, I., Stein-Parbury, J., Gill, K., \& Heffernan, T. (2015). "Making it real": Facilitating recovery-focused nursing practice through consumer participation in the development of 
innovative and technology-rich learning experiences for final year nursing students. Paper presented at The Mental Health Services Conference, Canberra.

Robinson, K., \& Webber, M. (2013). Models and effectiveness of service user and carer involvement in social work education: A literature review. British Journal of Social Work, 43(5), 925-944. doi:10.1093/bjsw/bcs025

Scheyett, A., \& Diehl, M. J. (2004). Walking our talk in social work education: Partnering with consumers of mental health services. Social Work Education, 23(4), 435-450. doi:10.1080/0261547042000245035

Slay, J., \& Stephens, L. (2013). Co-production in mental health: A literature review. London: New Economics Foundation.

Stanbridge, R., \& Burbach, F. (2007). Developing family-inclusive mainstream mental health services. Journal of Family Therapy, 29(1), 21-43. doi:10.1111/j.1467-6427.2007.00367.x

Tew, J., Gell, C., \& Foster, S. (2004). Learning from experience: Involving service users and carers in mental health education and training: Mental Health in Higher Education National Institute for Mental Heath in England. 


\section{Footnotes}

'The term 'people with lived experience' includes both individuals and their family members who have lived experience of mental distress and/or mental illness and/or mental health recovery. The term 'family' will be used in this paper as opposed to 'carer', as the term 'carer' is often contested as it implies a relationship of dependency and excludes other chosen identities (Stanbridge \& Burbach, 2007). 'Family' encapsulates whomever a service user may claim as family. 


\section{Figure 1}

The Valuing Lived Experience Project map showing completed and planned activities.

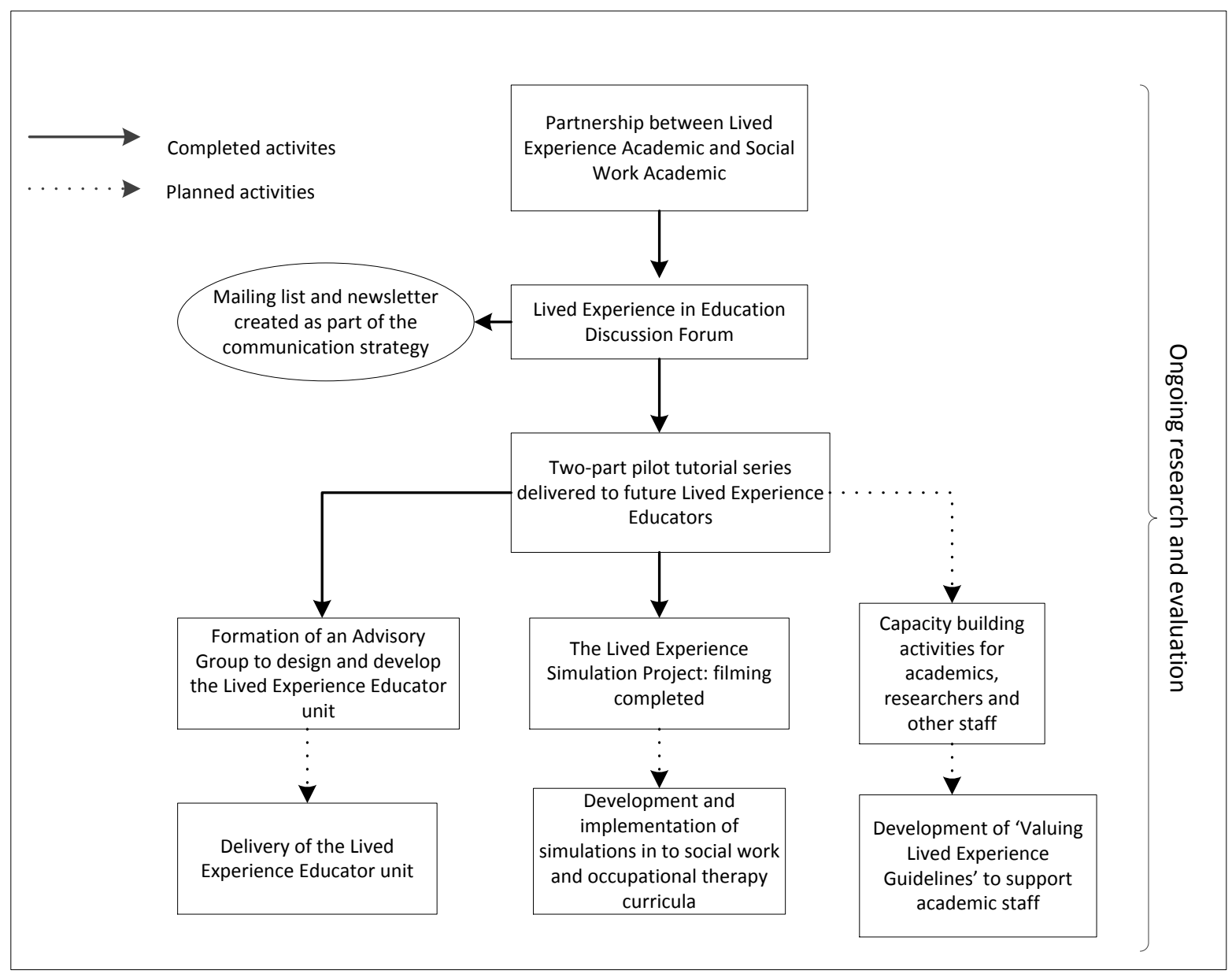


Table 1

The learning outcomes developed by the advisory group for the Lived Experience Educator unit.

Learning Outcomes of the Lived Experience Educator Unit

Describe the history of the consumer and family movement and the current concepts of involvement, participation and co-production in the lived experience involvement.

Apply contemporary mental health concepts of personal recovery, mental distress and 'madness' from a critically informed perspective, taking into account the global context and diverse frameworks of understanding.

Demonstrate application of self-awareness, self-reflection and self-care skills required of the lived experience educator role.

Demonstrate and apply the relevant academic concepts and practices that provide the context and inform the role of lived experience educators within the School. 
Table 2

Learning modules for the Lived Experience Educator unit

\begin{tabular}{|c|c|}
\hline Module & Examples of material covered \\
\hline $\begin{array}{l}\text { Introduction to the unit, the unit objectives and } \\
\text { assessments }\end{array}$ & 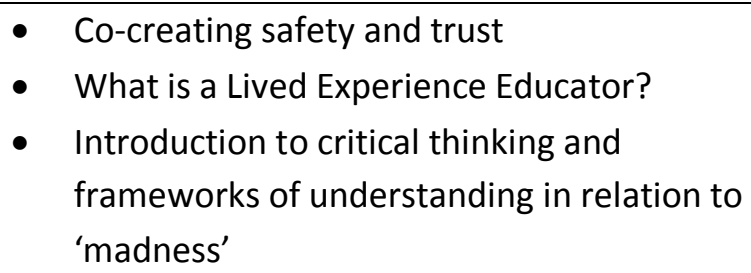 \\
\hline $\begin{array}{l}\text { History, current context, participation, } \\
\text { involvement and coproduction }\end{array}$ & $\begin{array}{l}\text { - Our Elders and histories of consumer and } \\
\text { recovery movements } \\
\text { Differences and similarities between } \\
\text { individual and family needs } \\
\text { - Wearing two hats: Can you advocate for } \\
\text { both consumer and family/carer } \\
\text { perspectives at once? }\end{array}$ \\
\hline Self-care, self-awareness, story and voice & $\begin{array}{l}\text { - Strategic use of story } \\
\text { - Self-compassion, self-nurture, resilience, } \\
\text { dealing with triggers } \\
\text { - Stepping into leadership }\end{array}$ \\
\hline Critical thinking & 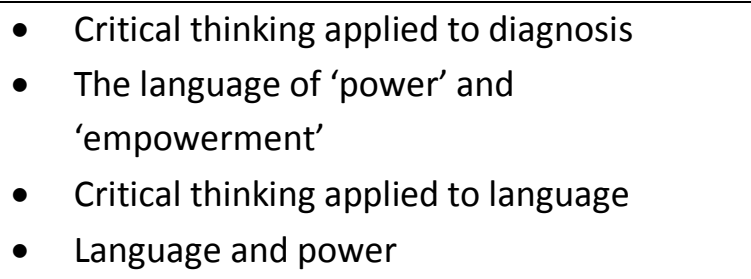 \\
\hline Recovery & $\begin{array}{l}\text { - Differentiating between personal, social } \\
\text { and clinical recovery } \\
\text { - } \quad \text { Critical thinking applied to 'recovery' } \\
\text { - } \quad \text { Maintenance, risk aversion and rescue }\end{array}$ \\
\hline $\begin{array}{l}\text { Understanding academia, practical matters, } \\
\text { teaching and learning skills }\end{array}$ & $\begin{array}{ll}\text { - } & \text { Marking rubrics } \\
\text { - } & \text { Unit outlines } \\
\text { - } & \text { Learning outcomes } \\
\text { - } & \text { Assessment guidelines } \\
\text { - } & \text { Skills audit } \\
\text { - } & \text { Creating a professional plan }\end{array}$ \\
\hline
\end{tabular}

